\title{
Microliter per Dose
}

National Cancer Institute

\section{Source}

National Cancer Institute. Microliter per Dose. NCI Thesaurus. Code C124466.

A unit of measure expressed in microliter(s) per dose. 